\title{
The Study of EFL Learners凹 Perception of Using E-learning and Self-Regulation in English classrooms: Teachers, intermediate and advanced learners' attitude
}

Marzie Faridi ( $\square$ m.faridi2@yahoo.com )

Original article

Keywords: E-learning, Self-regulated Learning

Posted Date: August 3rd, 2020

DOI: https://doi.org/10.21203/rs.3.rs-50003/v1

License: (a) (1) This work is licensed under a Creative Commons Attribution 4.0 International License. Read Full License 


\section{Abstract}

E-learning and self-regulation are kinds of autonomous learning. Some researchers have long been interested in E-

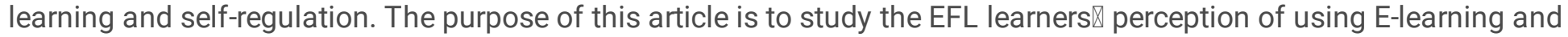
self-regulation in English classrooms. A quantitative research method was used for 360 intermediate, advanced learners and 34 teachers. Cluster sampling and convenience sampling method in order used for EFL learners and the teachers. Data gathered for six weeks in Zanjan English language institutes. The questionnaires were about advantages and disadvantages of e-learning and participants' perception on self-regulation capabilities by Likert scale that gave to the learners and teachers. Between group and within group investigated for both groups of participants. In general the results show the learners $₫$ positive attitude toward using self-regulation and advantages of E-learning in

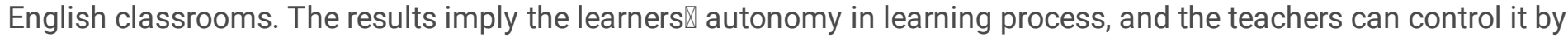
learners $₫$ attitude.

\section{Introduction}

E-learning is presently regarded as an innovation that will improve access to advanced educational experiences by allowing students and instructors to take part in far-flung learning communities. It can improve quality and effectiveness of education by supporting the collaborative learning process. Along with the rapid development of information technology (IT), the need for an IT-based concept and learning mechanism becomes inevitable. Therefore, one form of information technology has emerged, namely facilities for learning systems called e-learning(Wicaksono, 2020).

The findings of (Al-Fraihat, 2020) suggest increasing awareness among students about the usefulness and benefits of the e-learning system to increase its usability and popularity. This can be achieved by delivering workshops and training. Online learning environments are well-suited for tailoring the learning experience of children individually and on a large scale(de Mooij, 2020).

E-learning generally refers to methods of learning which use electronic instructional content delivered via the Internet and is a term which is synonymous with Web-based or online learning(Farhan, 2018). Research (Ayub, 2010; Su, 2008; Voogt, 2008) has shown that the use of technology, particularly computers and computer peripherals, in teaching generally improves the quality of teaching. The generalizability of computer self-efficacy refers to the perception by human beings of their capability to apply various computer software and hardware devices. Assessing educational atmosphere in e-learning settings by EEAM could provide managers and investors with useful information to settle an effective education system by prioritizing the necessary changes (Mousavi, 2020).

According to (Davis, 1986) beliefs about computers' usefulness and ease of use influences teachers' motivation to use computers in the classroom and later affects teachers' actual use of technology in their teaching practice. Creating an e-learning curriculum and presenting it through a learning management system as a virtual learning environment is a time consuming and resource hungry task(Hampel, 2014). Technologies might provide modern solutions to determine the students' attitudes towards the collaborative workspace (Bdiwi, 2019). Expanding e-learning brings several attractive opportunities for organizations: (1) saving time, cost and effort; (2) satisfying educational needs from remote areas; (3) providing self-learning opportunities; (4) having a positive impact on the learning process; and (5) providing a mechanism for collaborative learning (Moreira, 2017).

Technology-Enhanced Learning, progressively, has grown to be the area for research and practice on the application of information and communication technologies to teaching and learning (De Medio, 2020). An "e-learning task 
recommender" is a recommendation system that would recommend a learning task to a learner based on the tasks already done by the learner(Kulkarni, 2020).

In the self-regulated learning process, learners are understood to be active participants in their own learning and modify their actions, feelings and ideas in an real world situation as necessary. The e-Learning process can give rise to a spatial and temporal gap that poses interesting challenges for assessment of not only content, but also students' acquisition of core skills such as self-regulated learning(R. Cerezo, Bogarín,A. ,Esteban, M., \& Romero, C., 2020).

Students who lack self-regulation strategies may fail to comprehend or connect ideas in their pre-class learning, which could lead to ineffective learning outcomes during in-class activities(Zheng, 2020). Self-regulated learning is a kind of active and organized learning process. Learners set goals and then try to control and set their knowledge, motivation, and behavior (Peeters, 2016). Self-regulated learners are more likely to transfer skills to real-world situations from elearning environments successfully. The possibility of students and teachers to interact and the expansion of the geography of education should be noted among the prospects of modern management in the implementation of elearning(Vershitskaya, 2020).

E-learning is presently considered by many as an innovation which will improve access to advanced educational experiences by allowing students and teachers to participate in remote learning communities and to improve quality and effectiveness of education by supporting a collaborative learning process(Patrichi, 2016). The e-learning tools helped the students to self-regulate and discover their own knowledge, which increased their chances of handling application type problems(Akugizibwe, 2020).

The essence of self-regulated learning is the high motivation of the learners. In this study, one of the most important current discussions is to explore the use of e-learning in the area of learning and teaching. The article has a critical role to play in explaining the perception of EFL learners.

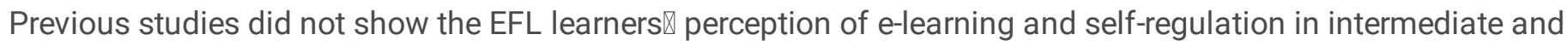
advanced levels. (Dashtestani, 2014) explored the Iranian EFL teachers $\triangle$ perceptions on the use of online instruction by conducting a mixed-method study questionnaire and semi-structured interview on $242 \mathrm{EFL}$ teachers filling in questionnaire phase of the study. In addition, $46 \mathrm{EFL}$ teachers were interviewed. Results from the study revealed that participants support rather positive attitudes toward the use of online instruction. But there are some barriers to online instruction in classrooms. The e-learning gives the student time, and space flexibility, allowing better management that suits their needs in education. In these learning systems, one of the most important roles of the teacher is being the mediator/facilitator.

The aim of the present research is to explore the perception of EFL learners $\$ perception of using e-learning and selfregulated learning in intermediate and advanced levels in English classrooms and teacher participants. Participants of this study were 360 intermediate and advanced learners. The goal of this study was to answer the flowing research questions:

1. What is the EFL learners' perception of using self-regulation in English classrooms?

2. What is the EFL learners' perception on the advantages and disadvantages of using e-learning in English classrooms?

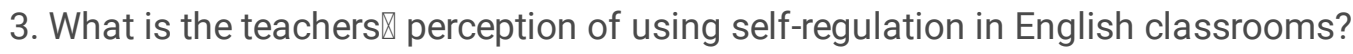

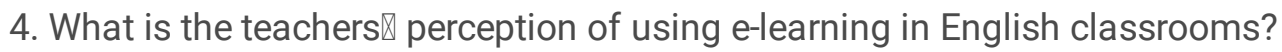

\section{Literature Review}

2.1.1 E-learning

Page $3 / 17$ 
E-learning or electronic learning, is the delivery of learning and training through digital resources. This study investigate these elements on EFL learners in English classrooms, the teachers, intermediate and advanced learners $\mathbb{Z}$ attitude toward using self-regulation, constructivism and advantages and disadvantages of e-learning. E-Learning has brought new opportunities to education (Commission, 2014) but also bring many challenges for the student, who has to decide what, when, how, and for how long to learn (R. Cerezo, Sánchez-Santillán, M., Paule-Ruiz, M. P., \& Núñez, J. C., 2016)

(Manuela Aparicioa, 2017) propose a theoretical model studying grit as a determinant of e-learning systems success. The study was conducted on a sample of university students' sample, and a theoretical model was validated using structural equation modeling (SEM). Results indicate that grit has positive effects on satisfaction and in students' individual performance.

2.1.2 Self-regulation

Self-regulated learning theory refers to the process, a learner involves in when takes responsibility for acquisition in learning. It happens in three steps: planning, monitoring and reflection.

(Rebeca Cerezo, 2019) applied a new algorithm in the educational domain called Inductive Miner over the interaction traces from 101 university students in a course given over one semester on the Moodle 2.0 platform. Data was extracted from the platform's event logs with 21,629 traces in order to discover students' self-regulation models that contribute to improving the instructional process. It concludes that although students who passed did not follow the instructors' suggestions exactly, they did follow the logic of a successful self-regulated learning process as opposed to their failing classmates.

\section{Method}

In this quantitative study, a descriptive method used to determine the EFL learners' perception of using e-learning and self-regulated in English classrooms. In this study the quantitative and correlational information collected through Obafemi Questionnaires (2015), a quick placement test to investigate the learners' level. The participants were selected through a multistage cluster random sampling method. To grantee, the homogeneity of the participants, Quick Placement test (QPT) was used to test the proficiency level of the learners.

\subsubsection{Learner Participants}

The participants of this study were Iranian EFL learners in intermediate and advanced level of institutions in Zanjan province $(n=7000)$. According to Cochran formula size, 360 learners were needed as the sample size of the study, because of the limitation of easy access to institutions, four institutes were chosen as the target of this study between the total institutions $(n=116)$ in Zanjan province. The learners were chosen from (Melal language institute, Safir institute, and Omid language institute, Goldi's Institute) for these stages. We used questionnaires to investigate elearning, self-regulation of the learners. The type of sampling in this study was cluster random sampling. The participant's aged ranges were 13 to 14 , and 15 to 16, and they were about 20 learners in each class. We used a cluster sampling method for learners.

\subsubsection{Teacher Participants}

The other group was chosen by teachers as a convenience sampling method $(n=34)$. The teachers were both male, and female in Zanjan institutes to answer the questionnaires in self-regulation and e-learning. During six weeks the data collected through questionnaires for the learners and the teachers too. A descriptive research method was chosen for this study. A Likert scale used to investigate the research through questionnaires. It is the most widely used approach to scaling responses in this research.

\subsubsection{Instruments}


In this study, the participants $\otimes$ perceptions on Self-Regulation capabilities and e-learning (ICTs) advantages, and disadvantages sections of Obafemi Questionnaires (2015) were used that respectively consisted of 10 and 10 questions.

\subsubsection{Pilot Study}

The participants $₫$ perceptions on Self-Regulation capabilities and e-learning (ICTs) advantages and disadvantages sections of Obafemi Questionnaires (2015) were piloted on 30 advanced and intermediate with a similar educational background to obtain the reliability of the test. To be statistically acceptable, the internal consistency and reliability coefficient was measured using Cronbach Alpha. The test-retest reliability of these tests with the one-week interval was $(a=.84)$ which showed an acceptable reliability value.

\subsubsection{Backward and Forward Translation}

To be sure that the participant's reaction to Obafemi questionnaires was translated into the Persian language in selfregulation and e-learning. First, two expert translators were given the English version to translate into Persian, and then two other expert translators were asked to translate the Persian versions of the questionnaires into English, And these versions were compared by two other English-language experts with the original English questionnaires, and eventually, one of the Persian versions of the most suitable translated questionnaires was chosen as the current research questionnaire.

\subsubsection{Procedure}

In this study, two levels of students $(n=360)$ in English classrooms in intermediate, and advanced levels (Melal institute, Iranzamin, and Roozbeh) were chosen, and in each level, self-regulated learning and e-learning were investigated with a questionnaire that contained 10 items, for each one. During six weeks the data collected through questionnaires for the learners, and the teachers too. A descriptive research method was chosen for this study. A Likert scale used to investigate the research through questionnaires. It is the most widely used approach to scaling responses in this research.

The distribution method of research variables based on the most important central indexes of mean, dispersion, and the standard deviation was investigated. In Table 1, the descriptive statistics of the participants' interpersonal intelligence and frequency and types of informal fallacies and evidence were demonstrated.

\section{Data Analysis Of The First Research Question}

Data analysis among perceptions of teachers, intermediate, and advanced learners on self-regulation. A descriptive statistics among teachers, intermediate and advanced learners $₫$ perception on self-regulated learning. The mean and standard deviation of each group show in the Table 1. 
Table 1

Descriptive Statistics

\begin{tabular}{|llllll|}
\hline & N & Mean & Std. Deviation & Minimum & Maximum \\
\hline A1 & 394 & 3.2741 & 0.9169 & 2 & 5 \\
A2 & 394 & 4.0533 & 1.16335 & 1 & 5 \\
A3 & 394 & 3.3731 & 0.93307 & 1 & 5 \\
\hline A4 & 394 & 4.0508 & 0.90375 & 1 & 5 \\
A5 & 394 & 3.3985 & 0.83565 & 1 & 5 \\
A6 & 394 & 3.8959 & 0.9229 & 2 & 5 \\
A7 & 394 & 3.6168 & 0.8367 & 1 & 5 \\
\hline A8 & 394 & 4.2132 & 0.9053 & 1 & 5 \\
A9 & 394 & 4.4492 & 0.76082 & 2 & 5 \\
\hline A10 & 394 & 4.1777 & 0.83432 & 1 & 5 \\
\hline \multicolumn{4}{|l}{ Analytical results of the first series of questions about self-regulation } \\
\hline
\end{tabular}

According to the Table 2, there is a significant difference in $1 \%(\mathrm{P} \leq 1 \%)$ level between three groups of participants (teachers, intermediate, and advanced level of learners) in A1 to A5 of self-regulation questionnaire:

A1: Do not easily get distracted.

A2: Able to self-evaluate

A3: Able to reach goals without the help

A4: Able to learn from mistakes

A5: Able to take critical decisions

Based on Table 2 there is not a significant difference in $5 \%(p \geq 5 \%)$ level between three groups of participants in A6, and $\mathrm{A} 10$ of the self-regulation questionnaire.

A6: Have personal standards A7: Able to deal with unexpected situations

A8: Able to seek advice A9: Have willpower

A10: Know what they want to be in the future

We used chi-square to analyze three groups of participants $\Downarrow$ perception on self-regulation that demonstrated in Table 2. 
Table 2

Test Statistics ${ }^{\mathrm{a}, \mathrm{b}}$

\begin{tabular}{|lllllllllll|}
\hline & A1 & A2 & A3 & A4 & A5 & A6 & A7 & A8 & A9 & A10 \\
\hline Chi-Square & 9.272 & 36.436 & 42.167 & 14.557 & 23.061 & 2.725 & 3.205 & 4.853 & 5.359 & 0.166 \\
\hline df & 2 & 2 & 2 & 2 & 2 & 2 & 2 & 2 & 2 & 2 \\
\hline Asymp. Sig. & 0.01 & 0 & 0 & 0.001 & 0 & 0.256 & 0.201 & 0.088 & 0.069 & 0.921 \\
\hline a. Kruskal Wallis Test & & & & & & & & & \\
\hline
\end{tabular}

1. Grouping Variable: answering group ( Table 2)

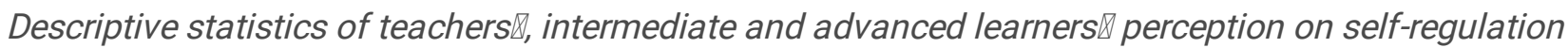

In Table 3 there is no significant difference in $5 \%(p \geq 5 \%)$ level between two groups of learners $₫$ perception on using self-regulation questionnaire ( $A 1$ to $A 10$ ).

We used man-Whitney to analyze differences between the two groups of learners.

Table 3

Test Statistics $^{\mathrm{a}}$

\begin{tabular}{|c|c|c|c|c|c|c|c|c|c|c|}
\hline & A1 & A2 & A3 & A4 & A5 & A6 & A7 & A8 & A9 & A10 \\
\hline $\begin{array}{l}\text { Mann- } \\
\text { Whitney } \\
U\end{array}$ & 15390 & 15862 & 15069.5 & 15880 & 16044.5 & 16101 & 15240 & 15802.5 & 16010 & 15983.5 \\
\hline $\begin{array}{l}\text { Wilcoxon } \\
\text { W }\end{array}$ & 31680 & 32152 & 31359.5 & 32170 & 32334.5 & 32391 & 31530 & 32092.5 & 32300 & 32273.5 \\
\hline Z & -0.88 & -0.374 & -1.289 & -0.35 & -0.171 & -0.105 & -1.064 & -0.453 & -0.221 & -0.238 \\
\hline $\begin{array}{l}\text { Asymp. } \\
\text { Sig. (2- } \\
\text { tailed) }\end{array}$ & 0.379 & 0.709 & 0.197 & 0.726 & 0.864 & 0.916 & 0.287 & 0.65 & 0.825 & 0.812 \\
\hline a. Groupin & ariab & nswe & aroun & le 3) & & & & & & \\
\hline
\end{tabular}

Descriptive statistics of Intermediate, and advanced learners》 perception on self-regulation

According to Table 4 , there is a significant difference in $1 \%(p \leq 1 \%)$ level between two groups of teachers $\rrbracket$, and

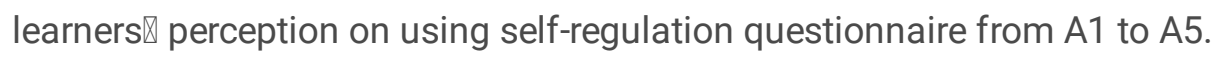

There is no significant difference in $5 \%(p \geq 5 \%)$ level between two groups of teachers $\llbracket$, and learners $\rrbracket$ perception on using self-regulation in answering the questions $A 6$, and $A 7$ of self-regulation questionnaire.

Based on Table 4 the results shows that there is a significant difference in $5 \%(1 \% \geq p \geq 5 \%)$ level between two groups of teachers $\rrbracket$, and learners $₫$ perception on using self-regulation in answering the questions $A 8$ ( $1 \% \geq 0.03 \geq 5 \%$, and A9 $(1 \% \geq 0.02 \geq 5 \%)$ of self-regulation questionnaire.

According to this Table, there is not a significant difference in $5 \%(p \geq 5 \%)$ level between the group 1 (teachers), and 2 (learners) in answering the question A10 ( $p \geq 0.7)$, and their perception on using self-regulation. 
Table 4

Test Statistics ${ }^{a}$

\begin{tabular}{|lllllllllll|}
\hline & A1 & A2 & A3 & A4 & A5 & A6 & A7 & A8 & A9 & A10 \\
\hline $\begin{array}{l}\text { Mann- } \\
\text { Whitney U }\end{array}$ & 4389 & 2567 & 2447.5 & 3881.5 & 3297 & 5123.5 & 5278 & 4888 & 4838.5 & 5927.5 \\
\hline Wilcoxon W & 4984 & 3162 & 3042.5 & 4476.5 & 3892 & 5718.5 & 5873 & 5483 & 5433.5 & 70907.5 \\
\hline Z & -2.915 & -6.027 & -6.364 & -3.799 & -4.799 & -1.648 & -1.446 & -2.158 & -2.303 & -0.329 \\
\hline $\begin{array}{l}\text { Asymp. Sig. } \\
\text { (2-tailed) }\end{array}$ & 0.004 & 0 & 0 & 0 & 0 & 0.099 & 0.148 & 0.031 & 0.021 & 0.742 \\
\hline \begin{tabular}{l} 
a. Grouping Variable: answering group (Table 4) \\
\hline
\end{tabular}
\end{tabular}

Descriptive statistics of teachers $\bigotimes$, and learners $\rrbracket$ perception on using self-regulation

\section{Data Analysis Of Second Research Question}

Data analysis among groups of teachers, intermediate, and advanced learners $\$ perception of e-learning. A descriptive statistics among the three groups of teachers, intermediate, and advanced learners $\varangle$ mean, and standard deviation shows in this table.

Table 5

Descriptive Statistics

\begin{tabular}{|llllll|}
\hline & N & Mean & Std. Deviation & Minimum & Maximum \\
\hline B1 & 393 & 3.6947 & 1.07542 & 1 & 5 \\
\hline B2 & 393 & 4.1832 & 0.91027 & 2 & 5 \\
\hline B3 & 393 & 3.7583 & 0.91757 & 2 & 5 \\
\hline B4 & 393 & 3.3842 & 1.04611 & 1 & 5 \\
\hline B5 & 393 & 3.5115 & 0.88381 & 1 & 5 \\
\hline B6 & 393 & 3.5547 & 0.94366 & 1 & 5 \\
\hline B7 & 393 & 3.7405 & 1.13111 & 1 & 5 \\
\hline B8 & 393 & 3.6056 & 1.02751 & 2 & 5 \\
\hline B9 & 393 & 3.6361 & 0.87331 & 1 & 5 \\
\hline B10 & 393 & 3.0891 & 1.27163 & 1 & 5 \\
\hline
\end{tabular}

Analytical results among the three groups of participants and their perception of advantages, and disadvantages of elearning shows in this Table.

According to Table 6, there is not a significant difference among three groups of teachers, intermediate, and advanced learners $\rrbracket$ perception in $5 \%(p \geq 0.05)$ level, in answering the question B1 (0.3 $\geq 0.05)$, B6 (0.2 $\geq 0.05)$, B8 (0.2 $\geq 0.05)$, B9 $(0.6 \geq 0.05)$, it means that the opinions of participants in these three groups are close to each other, and their perception on e-learning questionnaire. 
B1: putting teaching, and learning into context

B6: Providing dedicated attention to special needs students.

B8: Avoiding equipment problems in teaching, and learning.

B9: Reducing the cost of education.

Based on Table 6, the result shows that there is a significant difference among three groups in $5 \%(0.01 \geq p \geq 0.05)$ level, the questions B2 (0.01 $\geq 0.02 \geq 0.05)$, and B5 $(0.01 \geq 0.03 \geq 0.05)$, in answering the questions of e-learning questionnaire.

B2: Making teaching, and learning resources more available.

B5: Assessing learners' academic performance.

Again this Table shows a significant difference in $1 \%(\mathrm{p} \leq 0.01)$, between groups of teachers, intermediate, and advanced level of learners, the questions B3 (0.008 $\leq 0.01)$, B4 $(0.002 \leq 0.01)$, B7 (0.001 $\leq 0.01)$, and B10 (0.00 $\leq$ $0.01)$. The conclusion in these questions means that the participants $₫$ opinions are not similar to each other.

B3: Allowing more interactions between educators, and learners.

B4: Adhering to social, moral, and cultural practices.

B7: Alleviating teachers' workload.

B10: Minimizing health problems in teaching, and learning.

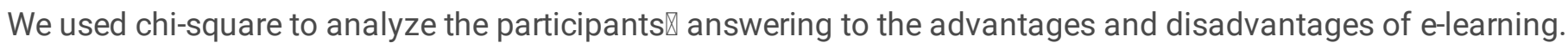

Table 6

Test Statistics ${ }^{\mathrm{a}, \mathrm{b}}$

\begin{tabular}{|lllllllllll|}
\hline & B1 & B2 & B3 & B4 & B5 & B6 & B7 & B8 & B9 & B10 \\
\hline Chi-Square & 2.273 & 7.104 & 9.545 & 12.241 & 6.779 & 3.124 & 14.922 & 2.879 & 0.885 & 15.424 \\
\hline df & 2 & 2 & 2 & 2 & 2 & 2 & 2 & 2 & 2 & 2 \\
\hline Asymp. Sig. & 0.321 & 0.029 & 0.008 & 0.002 & 0.034 & 0.21 & 0.001 & 0.237 & 0.642 & 0 \\
\hline $\begin{array}{l}\text { a. Kruskal Wallis Test } \\
\text { b. Grouping Variable: answering group (Table 6) }\end{array}$ & & & & & & & \\
\hline
\end{tabular}

A Descriptive statistics of teachers $\Downarrow$, intermediate and advanced learners $\Downarrow$ perception on e-learning.

According to Table 7, the results show that there is not a significant difference between two groups of learners (intermediate and advanced) in $5 \%(p \geq 0.05)$ level. In these questions B1 to B10 of

E-learning questionnaire, the participants $\Downarrow$ opinions are close to each other on e-learning advantages, and disadvantages. 
Table 7

Test Statistics ${ }^{\mathrm{a}}$

\begin{tabular}{|llllllllllll|}
\hline & B1 & B2 & B3 & B4 & B5 & B6 & B7 & B8 & B9 & B10 \\
\hline $\begin{array}{l}\text { Mann- } \\
\text { Whitney U }\end{array}$ & 14954 & 15508 & 14932 & 14831 & 14744 & 15117 & 15939 & 15567.5 & 15414 & 15762.5 \\
\hline Wilcoxon W & 31244 & 31798 & 31222 & 31121 & 31034 & 31407 & 32229 & 31857.5 & 31704 & 32052.5 \\
\hline Z & -1.387 & -0.764 & -1.358 & -1.444 & -1.67 & -1.185 & -0.276 & -0.666 & -0.851 & -0.465 \\
\hline $\begin{array}{l}\text { Asymp. } \\
\text { Sig. (2- }\end{array}$ & 0.166 & 0.445 & 0.174 & 0.149 & 0.095 & 0.236 & 0.783 & 0.506 & 0.395 & 0.642 \\
tailed) & & & & & & & & & & & \\
\hline
\end{tabular}

A Descriptive statistics of intermediate, and advanced learners $\Downarrow$ perception of advantages, and disadvantages on elearning.

Based on Table 8 the results show that there is not a significant difference in $5 \%(p \geq 0.05)$ level in these questions B1 $(0.6 \geq 0.05), B 6(0.1 \geq 0.05), B 8(0.1 \geq 0.05)$, and B9 $(0.7 \geq 0.05)$ of e-learning questionnaire. It means that the answering of participants is similar to each other.

The conclusions show that there is a significant difference in $5 \%(0.01 \geq p \geq 0.05)$ level in B2 and B5 with $(0.01 \geq$ $0.02 \geq 0.05)$.

According to Table 8, there is a significant difference for the rest of the questions B3, B4, B7, and B10 in $1 \%(p \leq 0.01)$ level. It means that the opinions among teachers and learners $\mathbb{Z}$ are not similar to each other.

Table 8

Test Statistics ${ }^{a}$

\begin{tabular}{|lllllllllll|}
\hline & B1 & B2 & B3 & B4 & B5 & B6 & B7 & B8 & B9 & B10 \\
\hline Mann-Whitney U & 5828 & 4816 & 4382 & 4079 & 4811 & 5177.5 & 3717 & 5221.5 & 5912 & 3629 \\
\hline Wilcoxon W & 6423 & 69796 & 4977 & 4674 & 5406 & 5772.5 & 4312 & 5816.5 & 6507 & 4224 \\
\hline Z & -0.504 & -2.233 & -2.891 & -3.349 & -2.305 & -1.595 & -3.936 & -1.47 & -0.349 & -4.121 \\
\hline $\begin{array}{l}\text { Asymp. Sig. (2- } \\
\text { tailed) }\end{array}$ & 0.614 & 0.026 & 0.004 & 0.001 & 0.021 & 0.111 & 0 & 0.141 & 0.727 & 0 \\
\hline
\end{tabular}

a. Grouping Variable: answering group (Table 8)

A descriptive statistic of teachers, and learners $₫$ perception on advantages, and disadvantages of e-learning.

\subsection{Within Group Analytical Results Of Participants}

The comparison of teachers $₫$ opinion on self-regulation and e-learning questionnaires shows in these Tables 9,10 . We can conclude that $A 1$ to $A 10$ and $B 1$ to $B 10$ in $1 \%(p \leq 0.01)$ level, there is a significant difference between 34 teachers $\rrbracket$ answering to the questionnaires. It means that their opinions are not similar to each other. 
Table 9

Within group analytical results of teachers $₫$ perception on self-regulation

\begin{tabular}{|lllllllllll|}
\hline & A1 & A2 & A3 & A4 & A5 & A6 & A7 & A8 & A9 & A10 \\
\hline Chi-Square & 33 & 33 & 33 & 33 & 33 & 33 & 33 & 33 & 33 & 33 \\
\hline Df & 2 & 4 & 3 & 4 & 3 & 3 & 4 & 4 & 3 & 4 \\
\hline Asymp. Sig. & 0 & 0 & 0 & 0 & 0 & 0 & 0 & 0 & 0 & 0 \\
\hline
\end{tabular}

Table 10

Within group analytical results of teachers $₫$ perception on e-learning

\begin{tabular}{|lllllllllll|}
\hline & B1 & B2 & B3 & B4 & B5 & B6 & B7 & B8 & B9 & B10 \\
\hline Chi-Square & 33 & 33 & 33 & 33 & 33 & 33 & 33 & 33 & 33 & 33 \\
\hline Df & 3 & 2 & 3 & 3 & 4 & 4 & 3 & 3 & 4 & 4 \\
\hline Asymp. Sig. & 0 & 0 & 0 & 0 & 0 & 0 & 0 & 0 & 0 & 0 \\
\hline
\end{tabular}

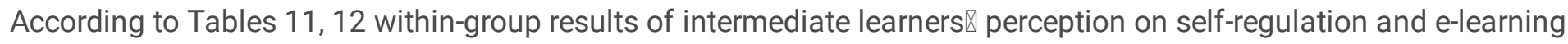
shows that there is significant difference between intermediate learners $₫$ opinion in $1 \%(p \leq 0.01)$ level in answering the questionnaires.

Table 11

Within group analytical results of Intermediate learners $₫$ perception on self-regulation

\begin{tabular}{|lllllllllll|}
\hline & A1 & A2 & A3 & A4 & A5 & A6 & A7 & A8 & A9 & A10 \\
\hline Chi-Square & 179 & 179 & 179 & 179 & 179 & 179 & 179 & 179 & 179 & 179 \\
\hline Df & 3 & 4 & 4 & 3 & 4 & 3 & 3 & 3 & 2 & 3 \\
\hline Asymp. Sig. & 0 & 0 & 0 & 0 & 0 & 0 & 0 & 0 & 0 & 0 \\
\hline
\end{tabular}

Table 12

Within group analytical results of Intermediate learners $₫$ perception on e-learning

\begin{tabular}{|llllllllllll|}
\hline & B1 & B2 & B3 & B4 & B5 & B6 & B7 & B8 & B9 & B10 \\
\hline Chi-Square & 179 & 179 & 179 & 179 & 179 & 179 & 179 & 179 & 179 & 179 \\
\hline Df & 4 & 3 & 3 & 4 & 3 & 4 & 4 & 3 & 3 & 4 \\
Asymp. Sig. & 0 & 0 & 0 & 0 & 0 & 0 & 0 & 0 & 0 & 0 \\
\hline
\end{tabular}

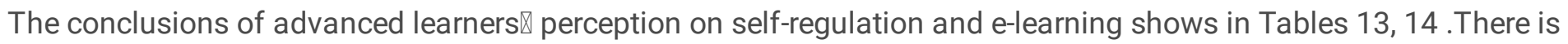
significant difference in $1 \%(p \leq 0.01)$ level between advanced learners $\mathbb{Z}$ answering to questionnaires we have ten questions in each questionnaire. 
Table 13

Within group analytical results of advanced learners $₫$ perception on self-regulation

\begin{tabular}{|lllllllllll|}
\hline & A1 & A2 & A3 & A4 & A5 & A6 & A7 & A8 & A9 & A10 \\
\hline Chi-Square & 179 & 179 & 179 & 179 & 179 & 179 & 179 & 179 & 179 & 179 \\
\hline Df & 3 & 4 & 4 & 3 & 4 & 3 & 3 & 3 & 2 & 3 \\
\hline Asymp. Sig. & 0 & 0 & 0 & 0 & 0 & 0 & 0 & 0 & 0 & 0 \\
\hline
\end{tabular}

Table 14

Within group analytical results of advanced learners $₫$ perception on e-learning

\begin{tabular}{|lllllllllll|}
\hline & B1 & B2 & B3 & B4 & B5 & B6 & B7 & B8 & B9 & B10 \\
\hline Chi-Square & 179 & 179 & 179 & 179 & 179 & 179 & 179 & 179 & 179 & 179 \\
\hline Df & 4 & 3 & 3 & 4 & 3 & 4 & 4 & 3 & 3 & 4 \\
\hline Asymp. Sig. & 0 & 0 & 0 & 0 & 0 & 0 & 0 & 0 & 0 & 0 \\
\hline
\end{tabular}

The cluster sampling method used to analyze three groups of teachers, intermediate, and advanced learners $\mathbb{Z}$ perception of self-regulation (Fig. 1) and e-learning (Fig. 2).

Figure 1, The conclusion of the cluster sampling method analyze of three groups of teachers, intermediate, and advanced learners' perception of self-regulation shows in Fig. 1.

As shown in Fig. 1 learners $\Downarrow$ opinion (intermediate and advanced) is at the same level. The teachers are at one level that means they are in a group by themselves.

In other words, intermediate and advanced learners $₫$ opinion is close to each other on self-regulation but the teachers have a different viewpoint or opinion on self-regulation.

The last figure of the cluster sampling method is about three groups of teachers, intermediate, and advanced learners $\Downarrow$ perception of e-learning. Analytical results of the cluster sampling method of two groups of learners are close to each other in Fig. 2; it means that their opinion on the third part of the questionnaire is in one group. We can see that the teachers $₫$ viewpoint is different from learners on the e-learning questionnaire.

Finally based on these two figures that described completely, the cluster sampling method of groups of intermediate, and advanced learners $₫$ opinion is close to each other than teachers $₫$ opinion on self-regulation and e-learning.

Cronbach's alpha (a) coefficients for all the variables for the

Table 15

Data Validity, and Reliability Results

\begin{tabular}{|lll|}
\hline Research Variable & No of items & Cronbach's Alpha (a) \\
\hline Perceived Self-Regulation & 10 & 0.894 \\
\hline Perception of the Advantages, and Disadvantages of e-learning & 10 & 0.924 \\
\hline
\end{tabular}

\section{Discussion}


E-learning is the use of telecommunication technology to deliver information or knowledge available to learners regardless of time restrictions or geographic proximity, and the learning environment is emerging as the new paradigm in education (Shee, 2008). (Koohang, 2005) define e-learning as "the delivery of education through various electronic media. According to(Cho, 2013), self-regulated learning (SRL) refers to a process, “... in which individuals take the initiative, with or without the help of others, in diagnosing their learning needs, formulating learning goals, identifying human, and material resources for learning, choosing and implementing appropriate learning strategies and evaluating learning outcomes".

The review of the previous literature has revealed a range of issues relating to the (Dashtestani, 2014) explored the

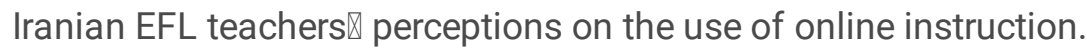

In this study the participants were two groups of the EFL learners in intermediate and advanced level and a group of teachers in English classrooms. The finding indicated that the majority of intermediate and advanced learners have positive attitudes toward using e-learning in English classrooms. Since teachers occupy pivotal role in controlling the class, within group analytical results showed that these three groups of participants have positive attitude. Between groups analytical results about advantages and disadvantages of using e-learning in English classrooms are different from both groups of learners. This finding contradicts with the previous research results that found teachers have positive attitude towards using online instruction and using e-learning.

(Hu, 2013) A mixed-methods study was conducted to examine the effects of self-regulated learning (SRL) strategy training on learners' achievement, motivation and strategy use in a web enhanced College Success course at a community college in southeast US. The participants in this study were 21 (8 treatment vs. 13 control) undergraduate students enrolled in 2 sections of the course. The participants were freshmen $(N=18)$ and sophomores $(N=3)$, whose ages ranged from 17 to $24(\mathrm{M}=18.9)$. Fifteen $(71 \%)$ of the participants were female and $6(29 \%)$ were male. They were made up of 7 (33\%) African Americans, 13 (62\%) Caucasians, and 1 (5\%) Hispanic. Five (62.5\%) participants in the treatment and seven (53.8\%) in the control condition were required to take this College Success course because of deficiency on College Placement Test. Only students who completed all the intervention procedures constituted the participants in this study, and comparison between the pre- and post-intervention results were made on exactly the same set of individuals. The findings of this study suggested that the training on SRL strategies might be beneficial to learners' persistence.

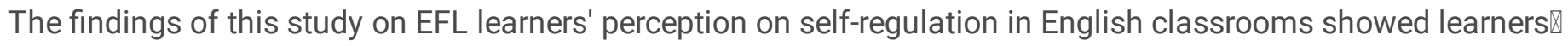
positive attitude toward using self-regulation. The intermediate and advanced learners have similar opinion to using self-regulation. The learners control their learning environment, practice their learning by directing and regulating their own actions toward their learning goals. The results of this research question on using self-regulation commensurate with the previous study.

The cluster sampling results of this study showed that two groups of the learners have positive attitude toward advantages of e-learning and using self-regulation in English classrooms and the teachers' attitude are different from the learners. Their opinion are not in line with the learner participants.

The issue of online learning on EFL learners' perception of self-regulation and e-learning requires precise attention. Importantly, we need to evaluate the proper implementations of online learning for EFL learners in different ages and levels.

\section{Conclusion}


1. Based on the results of the first research question, perception to self-regulated learning is important for learners

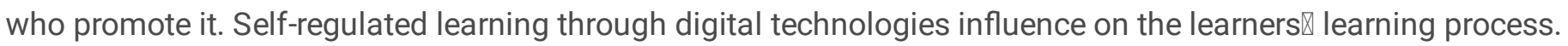

2. Based on the results achieved from the second research question, the learners $\$ perception of advantages, and disadvantages of e-learning that they had a positive attitude toward using e-learning in English classrooms. The results of this research question showed that the EFL learners in intermediate and advanced levels will use elearning in English classrooms.

3. The results of teachers $₫$ attitude toward using self-regulation, advantages and disadvantages of using e-learning in English classrooms showed their positive attitude toward using self-regulation and e-learning so teachers differ from learners on the use of e-learning and self-regulation.

Based on the results of data analysis and discussion, the conclusions that can be drawn from this research are, with elearning and self-regulation in English classrooms demonstrated to help teachers as a tool in clarifying the presentation of subject matter so as to increase student attention and enhance student learning effects, marked from the results of validation and advantages of e-learning and perception of self-regulation can increase the effectiveness of student learning results, student interests and create direct interactions between teachers and students, so that learning is more effective, efficient and interesting.

\section{Abbreviations}

WAN (wide area network), information and communication technology (ICT), Self-regulated learning (SRL), E-learning educational atmosphere measure (EEAM), information technology (IT), structural equation modeling (SEM), English as foreign language (EFL).

\section{Declarations}

\section{Availability of data and materials}

The data will be available upon requesting.

\section{Competing interests}

The authors declare that they have no competing interests.

\section{Funding}

The study did not receive any funding.

\section{Authors' contributions}

All authors of the research had more or less equal contributions in the process of conception design, acquisition of data analysis and interpretation of data. They have all been involved in revising the manuscript critically to the same extent. All take public responsibility for the whole content. All are equally accountable for all aspects of the work. All authors read and approved the final manuscript. 


\section{Acknowledgements}

Not applicable.

\section{References}

1. Akugizibwe, E., \& Ahn, J. Y. (2020). Perspectives for effective integration of e-learning tools in university mathematics instruction for developing countries. Education and Information Technologies, 25(2), 889-903.

2. Al-Fraihat, D., Joy, M., \& Sinclair, J. (2020). Evaluating E-learning systems success: An empirical study. Computers in Human Behavior, 102, 67-86.

3. Ayub, A., Mokhtar, M., Luan, ,W., \& Tarmizi, R. (2010). A comparison of two different technologies tools in tutoring Calculus. Procedia Social and Behavioural Science, 2(2), 481-486.

4. Bdiwi, R., et al.,. (2019). 'Smart learning environment: teacher's role in assessing classroom attention',. Research in Learning Technology, vol. 27, p. 2072. doi: 2010.25304/rlt.v25327.22072.

5. Cerezo, R., Bogarín, A., Esteban, M., \& Romero, C. (2020). Process mining for self-regulated learning assessment in e-learning. Journal of Computing in Higher Education, 32(1), 74-88.

6. Cerezo, R., Sánchez-Santillán, M., Paule-Ruiz, M. P., \& Núñez, J. C. (2016). Students' LMS interaction patterns and their relationship with achievement: A case study in higher education. Computers \& Education, 96, 42-54.

7. Cho, M. H., \& Kim, B. J. (2013). Students' self-regulation for interaction with others in online learning environments. The Internet, and Higher Education, 17, 69-75.

8. Commission, E. (2014). New modes of learning and teaching in higher education. Luxembourg: European Union.

9. Dashtestani, R. (2014). English as a foreign language-teachers' perspectives on implementing online instruction in the Iranian EFL context. Research in Learning Technology, 22(1), 20142.

10. Davis, F. D. (1986). A Technology Acceptance Model for Empirically Testing New End-User Information Systems: Theory and Results. Cambridge: PHD).

11. De Medio, C., Limongelli, C., Sciarrone, F., \& Temperini, M. (2020). MoodleREC: A recommendation system for creating courses using the moodle e-learning platform. Computers in Human Behavior, 104, 106168.

12. de Mooij, S. M., Kirkham, N. Z., Raijmakers, M. E., van der Maas, H. L., \& Dumontheil, I. (2020). Should online math learning environments be tailored to individuals' cognitive profiles? Journal of experimental child psychology, 191, 104730.

13. Farhan, M., Jabbar, S., Aslam, M., Hammoudeh, M., Ahmad, M., Khalid, S., ... Han, K. (2018). loT-based students interaction framework using attention-scoring assessment in eLearning. Future Generation Computer Systems, 79, 909-919.

14. $10.17700 /$ jai.12014.17705.17701.17124

Hampel, G. D., K. (2014). 'Creating a virtual learning environment',. Journal of Agricultural Informatics, vol. 5, no. 1, pp. 46-55. doi: 10.17700/jai.12014.17705.17701.17124.

15. Hu, H., \& Driscoll, M. P. (2013). Self-Regulation in e-Learning Environments: A Remedy for Community College? Educational Technology \& Society, 16(4), 171-184.

16. Koohang, A. H., K (2005). Open source: A metaphor for e-learning. Informing Science. The International Journal of an Emerging Transdiscipline, 8, 75-86.

17. Kulkarni, P. V., Rai, S., \& Kale, R. (2020). Recommender System in eLearning: A Survey. In Proceeding of International Conference on Computational Science and Applications, (pp. 119-126). Springer, Singapore. 
18. Manuela Aparicioa, F. B., \& Oliveira, T. (2017). Grit in the path to e-learning success. Computers in Human Behavior, 66, 388-399.

19. Moreira, F., Ferreira, M. J., Santos, C. P., \& Durão, N. (2017). Evolution and use of mobile devices in higher education: A case study in Portuguese Higher Education Institutions between 2009/2010 and 2014/2015. Telematics and Informatics, 34(6), 838-852.

20. Mousavi, A., Mohammadi, A., Mojtahedzadeh, R., Shirazi, M., \& Rashidi, H. (2020). E-Learning Educational Atmosphere Measure (EEAM): A New Instrument for Assessing E-Students' Perception of Educational Environment. Research in Learning Technology, 28, 17-35.

21. Patrichi, B., Prelipceanu, D., Manuc, D., Ravariu, C., \& Babarada, F. (2016). Bio and Micro-Electronics eLearning by Online Collaborative Support. Procedia Technology, 22, 1160-1168.

22. Peeters, J., De Backer, F., Kindekens, A., Triquet, K., \& Lombaerts, K. (2016). Teacher differences in promoting students' self-regulated learning: Exploring the role of student characteristics. Learning and Individual Differences, $52,88-96$.

23. Rebeca Cerezo, A. B., María, E., \& Cristóbal, R. (2019). Process mining for self-regulated learning assessment in elearning. Journal of Computing in Higher Education, 32, 74-88.

24. Shee, D., \& Wang, Y. H. (2008). Multi-criteria evaluation of the web-based e-learning system: a methodology based on learner satisfaction and its applications. Computers \& Education, 50, 894-905.

25. Su, K. D. (2008). An integrated science course designed with information communication technologies to enhance university students' learning performance. Computer Education, 51(3), 1365-1374.

26. Vershitskaya, E. R., Mikhaylova, A. V., Gilmanshina, S. I., Dorozhkin, E. M., \& Epaneshnikov, V. V. (2020). Presentday management of universities in Russia: Prospects and challenges of e-learning. Education and Information Technologies, 25(1), 611-621.

27. Voogt, J. (2008). IT and curriculum processes: Dilemmas and challenges. In J. Voogt \& G. Knezek (Eds.). NewYork: Springer.

28. Wicaksono, A., Florentinus, T. S., \& Ahmadi, F. (2020). Development of E-Learning in Web Programming Subjects for Moodle Based Vocational Students.. Innovative Journal of Curriculum and Educational Technology „1 1-9.

29. Zheng, B., Ward, A., \& Stanulis, R. (2020). Self-regulated learning in a competency-based and flipped learning environment: learning strategies across achievement levels and years. Medical education online, 25(1), 1686949.

\section{Figures}

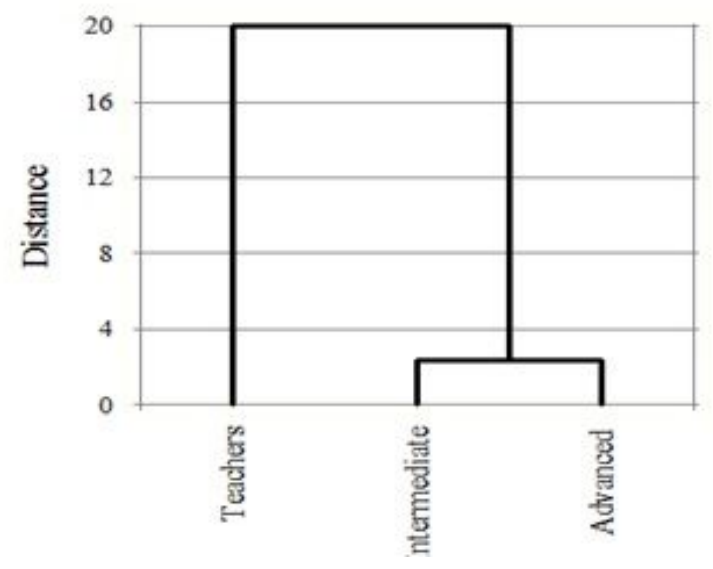


Figure 1

analytical result of groups on self-regulation

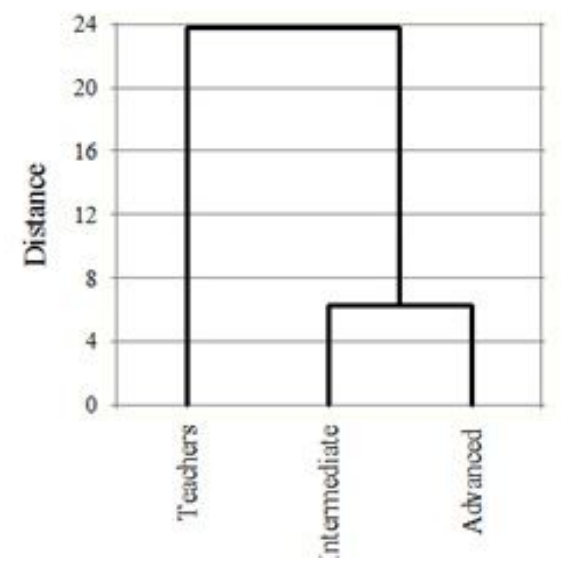

Figure 2

analytical results of groups on e-learning 